\title{
Association Between Val66Met Brain-Derived Neurotrophic Factor (BDNF) Gene Polymorphism and Post-Treatment Relapse in Alcohol Dependence
}

\author{
Marcin Wojnar, Kirk J. Brower, Stephen Strobbe, Mark Ilgen, Halina Matsumoto, \\ Izabela Nowosad, Elzbieta Sliwerska, and Margit Burmeister
}

\begin{abstract}
Background: The purpose of this study was to examine relationships between genetic markers of central serotonin (5-HT) and dopamine function, and risk for post-treatment relapse, in a sample of alcohol-dependent patients.

Methods: The study included 154 patients from addiction treatment programs in Poland, who met DSM-IV criteria for alcohol dependence. After assessing demographics, severity of alcohol use, suicidality, impulsivity, depression, hopelessness, and severity of alcohol use at baseline, patients were followed for approximately 1 year to evaluate treatment outcomes. Genetic polymorphisms in several genes (TPH2, SLC6A4, HTR1A, HTR2A, COMT, and BDNF) were tested as predictors of relapse (defined as any drinking during follow-up) while controlling for baseline measures.

Results: Of 154 eligible patients, $123(80 \%)$ completed follow-up and $48 \%(n=59)$ of these individuals relapsed. Patients with the Val allele in the Val66Met BDNF polymorphism and the Met allele in the Val158Met COMT polymorphism were more likely to relapse. Only the $B D N F$ $\mathrm{Val} / \mathrm{Val}$ genotype predicted post-treatment relapse [odds ratio $(\mathrm{OR})=2.62 ; p=0.019$ ], and time to relapse $(\mathrm{OR}=2.57 ; p=0.002)$, after adjusting for baseline measures and other significant genetic markers. When the analysis was restricted to patients with a family history of alcohol dependence $(n=73)$, the associations between the BDNF Val/Val genotype and relapse $(\mathrm{OR}=5.76, p=0.0045)$ and time to relapse (hazard ratio $=4.93, p=0.001)$ were even stronger.

Conclusions: The Val66Met $B D N F$ gene polymorphism was associated with a higher risk and earlier occurrence of relapse among patients treated for alcohol dependence. The study suggests a relationship between genetic markers and treatment outcomes in alcohol dependence. Because a large number of statistical tests were conducted for this study and the literature on genetics and relapse is so novel, the results should be considered as hypothesis generating and need to be replicated in independent studies.
\end{abstract}

Key Words: Alcohol Dependence, Genetic Polymorphism, Brain-Derived Neurotrophic Factor, Relapse.

A LCOHOL DEPENDENCE IS a cause of major health, social, and economic problems. Within Poland, it affects about 4 to $9 \%$ of the population and causes about 10,000 deaths per year (GUS, 2006). The course of alcohol dependence is characterized by a persistent vulnerability to relapse and most treated individuals achieve only short-term periods of abstinence, regardless of the type of therapy that is

From the Department of Psychiatry ( $M W, K J B, S S, M I, M B)$, Molecular \& Behavioral Neuroscience Institute (ES, MB), University of Michigan, Ann Arbor, Michigan; Department of Psychiatry, Medical University of Warsaw (MW, HM, IN), Warsaw, Poland; Department of Veterans Affairs (MI), Health Services Research \& Development, Ann Arbor, Michigan.

Received for publication July 10, 2008; accepted November 13, 2008.

Reprint requests: Marcin Wojnar, MD, PhD, University of Michigan Addiction Research Center, Rachel Upjohn Building, 4250 Plymouth Road, Ann Arbor, MI 48109; Fax: 734-998-7992; E-mail:mwojnar@umich.edu

Copyright (C) 2009 by the Research Society on Alcoholism.

DOI: $10.1111 /$ j.1530-0277.2008.00886.x received (Polich et al., 1980; Project MATCH, 1997). An improved understanding of the underlying basis for relapse susceptibility in alcohol dependence may help to identify individuals at risk and facilitate more precise targeting of effective treatments.

A number of biological markers, including genetic polymorphisms, have been associated with a predisposition to develop alcohol dependence (Covault et al., 2004; Edenberg, 2007; Edenberg and Foroud, 2006; Edenberg and Kranzler, 2005; Gscheidel et al., 2000). However, biological predictors of relapse in alcohol dependence have been systematically investigated only in a few studies. The results from this research indicates that central dopamine (DA) hypofunction (Schmidt et al., 1996), increased density of striatal dopaminergic D2 receptors (Guardia et al., 2000), and decreased plasma $\beta$ endorphin levels (Marchesi et al., 1997) are potential markers of increased risk of relapse in alcohol dependence. Other studies have shown that polysomnographic-recorded sleep disturbances (Brower et al., 1998; Gann et al., 2001), fast beta 
power or other electroencephalogram abnormalities (Bauer, 2001), and changes in event-related potentials (Glenn et al., 1993) might be biological markers of risk for relapse. The relationship between serotonergic activity and vulnerability to alcohol relapse has received considerably less attention than the dopaminergic system. In the only study of which we are aware, George and colleagues (1999) reported a correlation between higher baseline concentrations of serotonin (5-HT) metabolites in cerebrospinal fluid and relapse in alcoholic patients.

The study of genetic vulnerability in predicting relapse in alcohol-dependent patients is far less common than genetic studies of initial onset or early risk. Most existing research on genetic vulnerability and relapse has examined potential associations using relatively small samples of alcohol-dependent patients admitted for alcohol detoxification. In a sample of 89 alcoholic patients followed for 12 months after admission, for example, Finckh and colleagues (1997) found no evidence for a significant relationship between the DA D2 receptor gene polymorphism in exon 8 and incidence of relapse. Also, other groups (Heinz et al., 1996; Wiesbeck et al., 2003) reported no evidence that particular D1, D2, or D3 DA receptor gene variants had any association with treatment outcomes in small samples of patients ( $N=97$ and $N=136$, respectively) followed for 6 or 12 months after inpatient admission. In a recent study, Pinto and colleagues (2008) reported that the $\mathrm{S}$ allele of the 5-HT transporter (5-HTT)-linked polymorphic region (5-HTTLPR) may have increased the risk of relapse in 48 alcohol-dependent patients. Also, recently, Bauer and colleagues (2007) reported the promising finding in a large sample of 812 subjects treated in Project MATCH that the G-allele of the GABRA2 gene, which codes for a subunit of the $\gamma$-aminobutyric acid receptor, was associated with significantly increased probabilities of both drinking and heavy drinking during and after treatment. Interestingly, the GABRA2 genotype also predicted differential treatment outcomes as a function of the psychotherapy that subjects' received during treatment.

Given the importance of better understanding relapse, we previously examined baseline psychosocial predictors of relapse including psychopathology, impulsivity, depression, hopelessness, and impulsive suicide attempts (Wojnar et al., 2008). Here, we extend those findings to explore genetic predisposition to relapse in alcohol dependence that might be related to 5-HT or DA system dysfunction. Specifically, we selected 6 genetic polymorphisms that have previously been associated with suicidality or impulsivity in alcohol-dependent individuals, in the genes encoding tryptophan hydroxylase type 2 (TPH2) (Stoltenberg et al., 2006; Zhou et al., 2005), the 5-HTT (Gorwood et al., 2000; Li and He, 2007; Pinto et al., 2008), 5-HT receptor 2A (HTR2A) (Lemonde et al., 2003; Serretti et al., 2007) and HTR2B (Preuss et al., 2001; Vaquero-Lorenzo et al., 2007), catechol- $O$-methyl transferase (COMT) (Kia-Keating et al., 2007; Wang et al., 2001), and brain-derived neurotrophic factor (BDNF) (Dwivedi et al., 2003; Iga et al., 2007; Matsushita et al., 2004). These 6 variants were tested for their association with vulnerability to relapse in a treatment sample of alcohol-dependent patients. As prior work has not examined the extent to which genetic factors may interact with a family history of alcohol dependence to predict relapse, we also analyzed the interaction of family history with genetic polymorphisms that were significantly associated with relapse in this study.

\section{MATERIALS AND METHODS}

\section{Participants}

One hundred and fifty-four patients consecutively admitted to addiction treatment programs in Warsaw, Poland, who met criteria for alcohol dependence participated in this prospective naturalistic study. Recruitment occurred at 4 abstinence-based treatment centers in Warsaw, Poland, including 2 outpatient and 2 residential alcohol treatment programs. A more detailed description of the study sample and the treatment programs has previously been published (Wojnar et al., 2008).

The majority of participants $(N=120 ; 77.9 \%)$ were recruited from residential treatment programs. Participants from these 2 settings differed in education level (mean 14.1, SD: 2.7 years for outpatients vs. mean 11.7, SD: 3.8 years for residential patients, $p=0.001)$ and employment status $(70.6 \%$ vs. $22.5 \%$, respectively; $p<0.001)$. The groups did not significantly differ in any other baseline characteristics. For the purposes of this study the 2 treatment groups were combined $(n=154)$.

Diagnoses using criteria from the Diagnostic and Statistical Manual of Mental Disorders, Fourth Edition (DSM-IV) (APA, 2000) were confirmed by consensus of a multidisciplinary team specializing in the treatment of addictions that included a psychiatrist and an addictions therapist. All study participants were European Caucasians. One hundred and twenty-three patients $(80 \%)$ completed a standardized follow-up assessment during the 12 months following baseline, which constituted the sample for this study. Further description of the study sample is provided in Table 1.

Patients with follow-up data $(n=123)$ were more likely than those without $(n=31)$ to be in a stable relationship (87\% vs. $71 \%$, $p=0.04$ ), have higher educational achievement (13.5 vs. 12.0 years; $p=0.04)$, and be employed $(86.3 \%$ vs. $71.6 \% ; p=0.04)$. Additionally, those with follow-up data drank less alcohol prior to the baseline assessment [mean: 183.2 (SD: 115.6) vs. 278.7 (179.5) g daily; $p=0.013]$ than those without follow-up data. However, these 2 groups did not differ in any other characteristics. The effect of missing follow-up data is presented below.

\section{Procedures}

After a complete description of the study was provided, including advance notification of follow-up procedures, written informed consent was obtained from all prospective participants. Both the Bioethics Committee at the Medical University of Warsaw and the University of Michigan Medical Institutional Review Board approved the research protocol and use of data for publication.

Patients then completed standardized assessments at baseline and approximately 1 year later. The baseline assessment included blood collection (lavender EDTA vacutainers) and questionnaires for evaluating psychopathology, depression, impulsivity, hopelessness, and alcohol use severity. Patients were followed for an average of approximately 12 months to evaluate treatment outcomes.

\section{Measures}

The Mini International Neuropsychiatric Interview (M.I.N.I.) (Sheehan et al., 1998) was used to assess suicide history. Patients were classified by the presence or absence of a suicide attempt in their lifetime. In patients with a past suicide attempt, attempts were further 
Table 1. Baseline Sociodemographic and Clinical Characteristics of Study Participants Who Remained Relapsed or Abstinent at 1-Year Follow-Up

\begin{tabular}{|c|c|c|c|}
\hline Characteristics & Relapsed $(n=59)$ & Abstinent $(n=64)$ & $p^{*}$ \\
\hline Age (years); mean (SD) & $44.15(10.06)$ & $44.39(8.90)$ & 0.890 \\
\hline Gender (males); $N(\%)$ & $45(76.3)$ & $45(70.3)$ & 0.456 \\
\hline Married; $N(\%)$ & $23(39.0)$ & $29(45.3)$ & 0.478 \\
\hline Family history of suicide; $N(\%)$ & $10(16.9)$ & $10(15.6)$ & 0.842 \\
\hline Family history of alcohol dependence; $N(\%)$ & $33(55.9)$ & $40(62.5)$ & 0.459 \\
\hline History of other substance use (past 1 month); $N(\%)$ & $10(16.9)$ & $8(12.5)$ & 0.486 \\
\hline Drinking days in past 3 months; median (IQR) & $15(2-49)$ & $4(0-35.75)$ & 0.032 \\
\hline Number of standard drinks per day; median (IQR) & $16.9(10.8-21.5)$ & $17.4(14.5-21)$ & 0.378 \\
\hline Severity of psychopathology (GSI; T-score); mean (SD) & $50.55(11.91)$ & $48.98(12.38)$ & 0.474 \\
\hline Severity of depression (BDI-II); mean (SD) & $21.07(11.93)$ & $18.42(11.69)$ & 0.219 \\
\hline Impulsiveness (BIS-11); mean (SD) & $72.13(9.87)$ & $70.85(10.76)$ & 0.497 \\
\hline Prior suicide attempt; $N(\%)$ & $29(49.2)$ & $24(37.5)$ & 0.192 \\
\hline Impulsive suicide attempt; $N(\%)$ & $20(33.9)$ & $10(15.6)$ & 0.018 \\
\hline Addiction treatment during follow-up (hours); median (IQR) & $29(0-106)$ & $48(16-133)$ & 0.136 \\
\hline $\begin{array}{l}\text { Anonymous Alcoholics attendance during follow-up } \\
\text { (number of meetings); median (IQR) }\end{array}$ & $11(0-45)$ & $24(4.5-44.5)$ & 0.315 \\
\hline
\end{tabular}

${ }^{*}$ Chi-square, t-test, or Mann-Whitney test were performed where appropriate. Significant tests are bolded. IQR, interquartile range; GSI, General Severity Index derived from Brief Symptom Inventory; BDI-II, Beck Depression Inventory version 2; BHS, Beck Hopelessness Scale; BIS-11, Barratt Impulsiveness Scale.

categorized as "impulsive" or "non-impulsive," as described in a previous paper (Wojnar et al., 2008).

Questions about demographics, family history, substance use, work functioning, legal problems, and social support were obtained using the University of Arkansas Substance Abuse Outcomes Module (SAOM), a self-administered questionnaire (Smith et al., 1996). Substance use questions included a 17-item severity of dependence scale. The SAOM has excellent test-retest reliability for the drinking questions (intraclass correlation coefficient $=0.87$ ) and concurrent validity with the Time-Line Follow-Back (TLFB) Interview $(r=0.74)$.

The Brief Symptom Inventory (BSI) (Derogatis and Melisaratos, 1983) was used to assess psychiatric severity. It is a validated, 53-item self-administered instrument that quantifies symptom distress in the past 7 days. Its General Severity Index was calculated as a $T$-score, which was keyed to healthy nonpatient subjects with separate norms for men and women.

The Barratt Impulsiveness Scale-11 (Barratt, 1959) was used to measure general impulsivity. It is a 30 -item self-report questionnaire that has been validated in substance-dependent individuals (Allen et al., 1998).

Severity of depression symptoms was measured using the Beck Depression Inventory II (BDI-II) (Beck et al., 1996). It has 21 items with total scores ranging from 0 (no depression) to 63 (severe depression). The reliability and validity of the BDI in mental health settings is well established.

To evaluate quantity and frequency of alcohol use both prior to (past 3 months) and during the study, the TLFB (Sobell et al., 1979, 1988) was administered at baseline and at follow-up assessment. Two primary outcomes were derived from TLFB data: (1) relapse to any drinking (yes/no) and (2) time to relapse to any drinking. Relapse was defined as any drinking during the follow-up period.

\section{Genotyping}

DNA was extracted from $7.5 \mathrm{ml}$ of fresh whole blood using Puregene Kits (Gentra Systems, Minneapolis, MN), and an aliquot of DNA was mailed in batches to the United States. Analyzed polymorphisms included: rs1386483 in the TPH2; C102T (rs6313) in the $H T R 2 A$; and 4 functional variants: the 5-HTTLPR (in locus SLC6A4); C(-1019)G (rs6295) in the HTR1A; Val158Met (rs4680) in the COMT; and Val66Met (rs6265) in the BDNF. 5-HTTLPR was genotyped by polymerase chain reaction (PCR) followed gel electrophoresis (Gelernter et al., 1998; Sen et al., 2004). The 5 single- nucleotide polymorphisms were genotyped using inventoried TaqMan assays according to the manufacturer's conditions and solutions (Applied Biosystems ABI, Foster City, CA). Assays were run on the University of Michigan DNA Core facility's ABI PRIZM 7900HT sequence analyzer. Genotyping error rate in the lab for the 5-HTTLPR repeat based on 472 samples was less than $1.4 \%$. This was determined as the discrepancy between 2 different sets of PCR primers and constitutes the upper bound as the method finally adopted was the more robust, and so we believe most of the discrepancy comes from the older methodology. For the TPH2 TaqMan assay, the genotyping error rate was $0 / 572$ by comparing 2 different assays. In general, TaqMan assay error rates in our lab are well below $1 \%$. Genotype frequencies did not deviate significantly from Hardy-Weinberg equilibrium.

\section{Statistical Analysis}

Between-group (relapsed or not) comparisons for genotype or allele frequency differences were performed using the chi-square test, or Fisher's exact test when necessary. Between-group differences for continuous variables were evaluated using the Student's $t$-test or ANOVA. Continuous data are presented as mean and SD.

Genetic polymorphisms and all baseline measures were analyzed as predictors of post-treatment relapse. Analyses focused on identifying associations between genetic polymorphisms and both rates of relapse and times to relapse. We began by examining the bivariate relationships between all genetic variants and relapse within the follow-up interval using chi-square analyses. In addition, for those patients who relapsed we compared the mean time to relapse among studied genotypes using ANOVAs.

Multivariate analyses examined the associations of genotypes with risk of relapse, after accounting for other baseline factors. Two separate multivariate analyses were performed: a multiple logistic regression analysis predicting relapse and a Cox proportional hazards regression analysis to predict time to relapse. Finally, Kaplan-Meier survival analyses were performed to test the relationships of genetic polymorphisms with probability of time to relapse.

\section{RESULTS}

Of 123 patients who completed the study, $73(59 \%)$ reported a family history of alcohol dependence. During the 
1-year follow-up interval, relapse to alcohol use occurred in $59(48 \%)$ patients, 48 of these returned to heavy drinking (defined as more than 4 drinks a day for more than 4 consecutive days), whereas 11 had just a brief lapse (drinking of a lesser amount or a shorter duration than heavy drinking). Among those who used any alcohol during the study, time to relapse was on average $218(\mathrm{SD}=133)$ days. There were no significant differences in relapse rates or time to relapse in patients with $(56 \% ; 208$ days) or without $(44 \% ; 216$ days) a family history of alcohol dependence $(p=0.459 ; p=0.645$, respectively).

The genotype and allele frequencies for all analyzed genetic polymorphisms [BDNF Val66Met, COMT Val158Met, HTR1A C(-1019)G, HTR2A C102T, 5-HTTLPR, and TPH2 rs1386483] in alcohol-dependent patients who relapsed and those who remained abstinent, post-treatment relapse rates for examined genotypes, and times to relapse are pre- sented in Table 2. Individuals with the Val allele of the $B D N F$ Val66Met polymorphism and the Met allele of the COMT Val158Met polymorphism were more likely to relapse than patients without these respective alleles. The highest relapse rates were observed in patients with the COMT Val/Met genotype and the BDNF Val/Val genotype (Table 2). Significantly shorter times to relapse were noted in individuals with the $B D N F \mathrm{Val} / \mathrm{Val}$ genotype than in the other $B D N F$ genotypes or other gene variants. Survival analysis also showed significant differences for $B D N F$ Val66Met genotypes, indicating that the Val/Val genotype was associated with highest risk for early relapse (log rank test: 7.68, $p=0.024$; Fig. 1). The COMT polymorphism was not associated with early relapse. For all other genetic markers, neither the genotypic nor allelic frequencies were significantly different when comparing patients who relapsed to those who remained abstinent.

Table 2. Genotype Distribution and Allele Frequencies in Analyzed Genetic Variants, and Their Relationship to Post-Treatment Relapse Rates and Times to Relapse

\begin{tabular}{|c|c|c|c|c|c|c|c|}
\hline & & $\begin{array}{c}\text { All participants } \\
n=123\end{array}$ & $\begin{array}{c}\text { Abstinent } \\
n=64 ; n(\%)\end{array}$ & $\begin{array}{c}\text { Relapsed } \\
n=59 ; n(\%)\end{array}$ & $\begin{array}{c}\text { Chi-square } \\
\text { statistic }\end{array}$ & $\begin{array}{c}\text { Relapse } \\
\text { rates (\%) }\end{array}$ & $\begin{array}{c}\text { ANOVA; } p^{\#} \\
\text { time to relapse } \\
\text { (days); mean (SD) }\end{array}$ \\
\hline \multicolumn{7}{|c|}{$B D N F$ Val66Met rs6265 $(n=119)^{*}$} & $\boldsymbol{F}=\mathbf{5 . 3 8 6 ;} p=0.006$ \\
\hline \multirow[t]{3}{*}{ Genotypes } & Val/Nal & $66(55.5)$ & $27(45.0)$ & $39(66.1)$ & 5.594 & 59.1 & $178(135)$ \\
\hline & Val/Met & $42(35.3)$ & 25 (41.7) & $17(28.8)$ & $p=0.061$ & 41.9 & $256(122)$ \\
\hline & Met/Met & $11(9.2)$ & $8(13.3)$ & $3(5.1)$ & & 27.3 & 260 (99) \\
\hline \multirow[t]{2}{*}{ Allele } & Val & $174(0.73)$ & $79(0.66)$ & $95(0.81)$ & 6.52 & 54.6 & \\
\hline & Met & $64(0.27)$ & $41(0.34)$ & $23(0.19)$ & $p=0.017$ & 35.9 & \\
\hline \multicolumn{7}{|c|}{ COMT Val158Met rs4680 $(n=115)^{*}$} & $F=1.113 ; p=0.332$ \\
\hline \multirow{3}{*}{ Genotypes } & Val/Val & $30(26.1)$ & $21(37.5)$ & $9(15.3)$ & 7.864 & 30.0 & $243(149)$ \\
\hline & Val/Met & $50(43.5)$ & $19(33.9)$ & $31(52.5)$ & $p=0.020$ & 62.0 & $202(127)$ \\
\hline & Met/Met & $35(30.4)$ & $16(28.6)$ & $19(32.2)$ & & 54.3 & $229(124)$ \\
\hline \multirow[t]{2}{*}{ Allele } & Val & $110(0.48)$ & $61(0.55)$ & $49(0.41)$ & 3.86 & 44.5 & \\
\hline & Met & $120(0.52)$ & $51(0.45)$ & $69(0.59)$ & $p=0.049$ & 57.5 & \\
\hline \multicolumn{7}{|c|}{ HTR1A C $(-1019) \mathrm{G}$ rs6295 $(n=113)^{*}$} & $F=1.307 ; p=0.275$ \\
\hline \multirow[t]{3}{*}{ Genotypes } & $\mathrm{CC}$ & $36(31.9)$ & $20(33.9)$ & $16(29.6)$ & 0.913 & 44.4 & $227(127)$ \\
\hline & CG & $54(47.8)$ & $29(49.2)$ & $25(46.3)$ & $p=0.634$ & 46.3 & $221(136)$ \\
\hline & GG & $23(20.4)$ & $10(16.9)$ & $13(24.1)$ & & 56.5 & $174(123)$ \\
\hline \multirow[t]{2}{*}{ Allele } & C & $126(0.56)$ & $69(0.58)$ & $57(0.53)$ & 0.74 & 45.2 & \\
\hline & $\mathrm{G}$ & $100(0.44)$ & $49(0.42)$ & $51(0.47)$ & $p=0.389$ & 51.0 & \\
\hline \multicolumn{7}{|c|}{ HTR2A C102T rs6313 $(n=113)^{\star}$} & $F=0.556 ; p=0.575$ \\
\hline \multirow[t]{3}{*}{ Genotypes } & $\mathrm{CC}$ & $38(33.6)$ & $17(28.8)$ & $21(38.9)$ & 1.893 & 55.3 & $200(125)$ \\
\hline & CT & $62(54.9)$ & $36(61.0)$ & $26(48.1)$ & $p=0.388$ & 41.9 & $228(129)$ \\
\hline & TT & $13(11.5)$ & $6(10.2)$ & 7 (13.0) & & 53.8 & $207(165)$ \\
\hline \multirow[t]{2}{*}{ Allele } & $\mathrm{C}$ & $138(0.61)$ & $70(0.59)$ & $68(0.63)$ & 0.31 & 49.3 & \\
\hline & $\mathrm{T}$ & $88(0.39)$ & $48(0.41)$ & $40(0.37)$ & $p=0.575$ & 45.5 & \\
\hline \multicolumn{5}{|c|}{ SLC6A4 5-HTTLPR $(n=112)^{*}$} & & & $F=0.041 ; p=0.960$ \\
\hline \multirow[t]{3}{*}{ Genotypes } & SS & $19(17.0)$ & $8(13.8)$ & $11(20.4)$ & 2.70 & 57.9 & $209(110)$ \\
\hline & SL & $47(42.0)$ & $22(37.9)$ & $25(46.3)$ & $p=0.259$ & 53.2 & $218(133)$ \\
\hline & LL & $46(41.1)$ & $28(48.3)$ & $18(33.3)$ & & 39.1 & $212(143)$ \\
\hline \multirow[t]{2}{*}{ Allele } & $S$ & $85(0.38)$ & $38(0.33)$ & $47(0.44)$ & 2.75 & 55.3 & \\
\hline & $\mathrm{L}$ & $139(0.62)$ & $78(0.67)$ & $61(0.56)$ & $p=0.097$ & 43.9 & \\
\hline \multicolumn{5}{|c|}{ TPH2 rs1386483 $(n=121)^{*}$} & & & $F=0.787 ; p=0.457$ \\
\hline \multirow{3}{*}{ Genotypes } & $\mathrm{CC}$ & $56(46.3)$ & $29(45.3)$ & $27(47.4)$ & 0.561 & 48.2 & $205(130)$ \\
\hline & CT & $54(44.6)$ & $28(43.8)$ & $26(45.6)$ & $p=0.756$ & 48.1 & 231 (133) \\
\hline & TT & $11(9.1)$ & $7(10.9)$ & $4(7.0)$ & & 36.4 & $248(143)$ \\
\hline \multirow[t]{2}{*}{ Allele } & C & $166(0.69)$ & $86(0.67)$ & $80(0.70)$ & 0.25 & 48.2 & \\
\hline & $\mathrm{T}$ & $76(0.31)$ & $42(0.33)$ & $34(0.30)$ & $p=0.617$ & 44.7 & \\
\hline
\end{tabular}

*Sample sizes vary because of difficulties in amplifying some samples; \#Pertains to differences in time to relapse. BDNF, brain-derived neurotrophic factor gene; COMT, catechol-O-methyl transferase gene; HTR1A, serotonin receptor $1 \mathrm{~A}$ gene; HTR2A, serotonin receptor 2A gene; 5-HTTLPR, serotonin transporter length promoter polymorphism; TPH2, tryptophan hydroxylase type 2 gene. Nominally statistically significant associations are indicated in bold. 


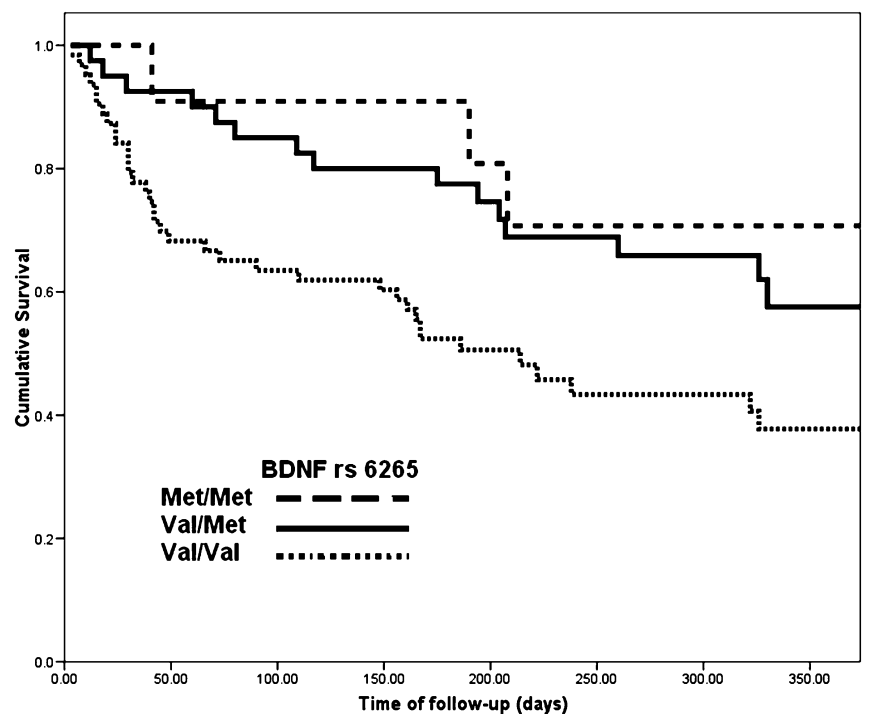

Fig. 1. Survival time to first relapse for Val66Met BDNF genotypes in patients with alcohol dependence $(n=123)$. Relapse $=$ any drinking in the follow-up. Survival analysis: Kaplan-Meier log rank statistics $=7.68, \mathrm{df}=1$, $p=0.024$.

We constructed logistic regression models to examine associations between genotypes, which showed significant associations in bivariate analyses, and post-treatment relapse, while adjusting for other potential risk factors for relapse in alcohol dependence. These variables, derived from our earlier findings (Wojnar et al., 2008), included baseline demographics (age and gender), severity of pretreatment alcohol use, severity of psychopathology, impulsivity, depression, and impulsive suicide attempts. The $B D N F$ $\mathrm{Val} / \mathrm{Val}$ genotype significantly predicted relapse [odds ratio $(\mathrm{OR})=2.62 ; 95 \%$ confidence interval $(\mathrm{CI})=1.18$ to 5.85 ; $p=0.019$ ] and time to relapse [hazard ratio $(\mathrm{HR})=2.57$; $95 \% \mathrm{CI}=1.30$ to $4.69 ; p=0.002$ ], while controlling for the COMT Val/Met genotype and other baseline measures (Tables 3 and 4). We reran this analysis without the COMT
Val/Met genotype in the model and the results remained the same.

An additional set of analyses was performed for patients who endorsed a family history of alcohol dependence $(n=73)$. In bivariate analyses, the predictive relationships between the $B D N F$ Val/Val genotype and relapse $(\mathrm{OR}=4.27 ; 95 \% \mathrm{CI}=1.53$ to $11.89 ; p=0.006)$, and time to relapse $(\mathrm{HR}=3.43 ; 95 \% \mathrm{CI}=1.47$ to $8.01 ; p=0.004)$ were significant in these individuals, but not in patients without a family history. In multivariate analyses (Tables 3 and 4), after controlling for the demographic and clinical measures previously listed, patients with a family history of alcohol dependence showed a more pronounced association between the $B D N F \mathrm{Val} / \mathrm{Val}$ genotype and relapse $(\mathrm{OR}=5.76$, $p=0.005)$ as well as time to relapse $(\mathrm{HR}=4.93$, $p=0.001$, which remained significant after correction for multiple testing. In addition, survival analysis of time to relapse in patients with a family history of alcohol dependence confirmed a significant relationship between the $B D N F$ Val66Met polymorphism and probability of early relapse (log rank test: $9.22, p=0.002$ ). Survival analysis in patients without family history was not significant (log rank test $=0.424$, $\mathrm{df}=1, p=0.515)$. There was a significant interaction between the BDNF Val66Met polymorphism and family history of alcohol dependence in the Cox regression model of risk of relapse in alcohol-dependent patients $(p=0.026$; Fig. 2.).

\section{Supplementary Analyses}

A series of additional analyses were undertaken to examine the effect of lack of follow-up data on the primary results. Earlier research has shown that individuals lost to follow-up are more likely to have relapsed than those with follow-up information (Bottlender and Soyka, 2005; Mann et al., 2005). Thus, we reclassified all participants with missing follow-up data as relapsed and reran the bivariate and multivariate analyses related to the $B D N F$ Val66Met polymorphism. These

Table 3. Logistic Regression Analysis for Predictors of Post-Treatment Relapse at 1-Year Follow-Up in Alcohol-Dependent Patients

\begin{tabular}{|c|c|c|c|c|c|c|}
\hline \multirow[b]{2}{*}{ Risk factors for relapse } & \multicolumn{3}{|c|}{ All patients $(n=123)$} & \multicolumn{3}{|c|}{$\begin{array}{l}\text { Patients with family history of alcohol } \\
\text { dependence }(n=73)\end{array}$} \\
\hline & OR & $95 \% \mathrm{Cl}$ & $p$ & OR & $95 \% \mathrm{Cl}$ & $p$ \\
\hline BDNF Val66Val genotype & 2.62 & $1.18-5.85$ & 0.019 & 5.76 & $1.64-20.31$ & 0.005 \\
\hline COMT Val158Met genotype & 1.30 & $0.53-3.16$ & 0.570 & 1.79 & $0.53-6.13$ & 0.351 \\
\hline Alcohol use at baseline ${ }^{*}$ & 1.02 & $1.00-1.03$ & 0.042 & 1.02 & $1.01-1.05$ & 0.033 \\
\hline Impulsive suicide attempts & 2.37 & $0.90-6.20$ & 0.080 & 2.52 & $0.55-11.47$ & 0.233 \\
\hline Age & 0.99 & $0.95-1.04$ & 0.696 & 0.97 & $0.91-1.04$ & 0.414 \\
\hline Severity of psychopathology (GSI) & 0.98 & $0.93-1.03$ & 0.483 & 1.00 & $0.93-1.08$ & 0.991 \\
\hline Gender & 1.07 & $0.96-1.21$ & 0.223 & 1.09 & $0.90-1.31$ & 0.374 \\
\hline Impulsiveness (BIS-11) & 1.00 & $0.95-1.05$ & 0.939 & 0.96 & $0.90-1.03$ & 0.301 \\
\hline Depression (BDI-II) & 1.01 & $0.95-1.08$ & 0.762 & 1.03 & $0.94-1.14$ & 0.503 \\
\hline
\end{tabular}

OR, adjusted odds ratio; $95 \% \mathrm{Cl}, 95 \%$ confidence interval for the OR; BDNF, brain-derived neurotrophic factor gene; COMT, catecholO-methyl transferase gene; GSI, General Severity Index derived from Brief Symptom Inventory; BDI-II, Beck Depression Inventory version 2; BIS-11, Barratt Impulsiveness Scale. Nagelkerke $r^{2}=0.197$; Nagelkerke $r^{2}=0.376$ (for family history of alcohol dependence). Nominally statistically significant associations are indicated in bold; *number of drinking days in the 90 days before baseline. 
Table 4. Cox Proportional Hazard Regression Analysis for Predictors of Time to Post-Treatment Relapse During 1-Year Follow-Up in Alcohol-Dependent Patients

\begin{tabular}{|c|c|c|c|c|c|c|}
\hline \multirow[b]{2}{*}{ Risk factors for time to relapse } & \multicolumn{3}{|c|}{ All patients $(n=123)$} & \multicolumn{3}{|c|}{$\begin{array}{l}\text { Patients with family history of alcohol } \\
\text { dependence }(n=73)\end{array}$} \\
\hline & $\mathrm{HR}$ & $95 \% \mathrm{Cl}$ & $p$ & $\mathrm{HR}$ & $95 \% \mathrm{Cl}$ & $p$ \\
\hline BDNF Val66Val genotype & 2.57 & $1.29-4.69$ & 0.002 & 4.93 & $1.92-12.68$ & 0.001 \\
\hline Impulsive suicide attempts & 1.97 & $1.07-3.63$ & 0.029 & 2.00 & $0.84-4.78$ & 0.119 \\
\hline Alcohol use at baseline ${ }^{\star}$ & 1.01 & $0.99-1.02$ & 0.124 & 1.02 & $1.01-1.03$ & 0.015 \\
\hline Age & 0.99 & $0.96-1.03$ & 0.829 & 0.96 & $0.91-1.01$ & 0.093 \\
\hline Impulsiveness (BIS-11) & 1.01 & $0.98-1.05$ & 0.536 & 0.99 & $0.95-1.04$ & 0.946 \\
\hline Gender & 1.06 & $0.53-2.10$ & 0.877 & 1.04 & $0.94-1.16$ & 0.430 \\
\hline Severity of psychopathology (GSI) & 0.99 & $0.97-1.03$ & 0.631 & 1.01 & $0.96-1.06$ & 0.634 \\
\hline Depression (BDI-II) & 1.02 & $0.97-1.06$ & 0.482 & 1.02 & $0.97-1.08$ & 0.383 \\
\hline
\end{tabular}

$\mathrm{HR}$, adjusted hazard ratio; $95 \% \mathrm{Cl}, 95 \%$ confidence interval for the hazard ratio; BDNF, brain-derived neurotrophic factor gene; GSI, General Severity Index derived from Brief Symptom Inventory; BDI-II, Beck Depression Inventory version 2; BIS-11, Barratt Impulsiveness Scale. Nominally statistically significant associations are indicated in bold; *number of drinking days in the 90 days before baseline.

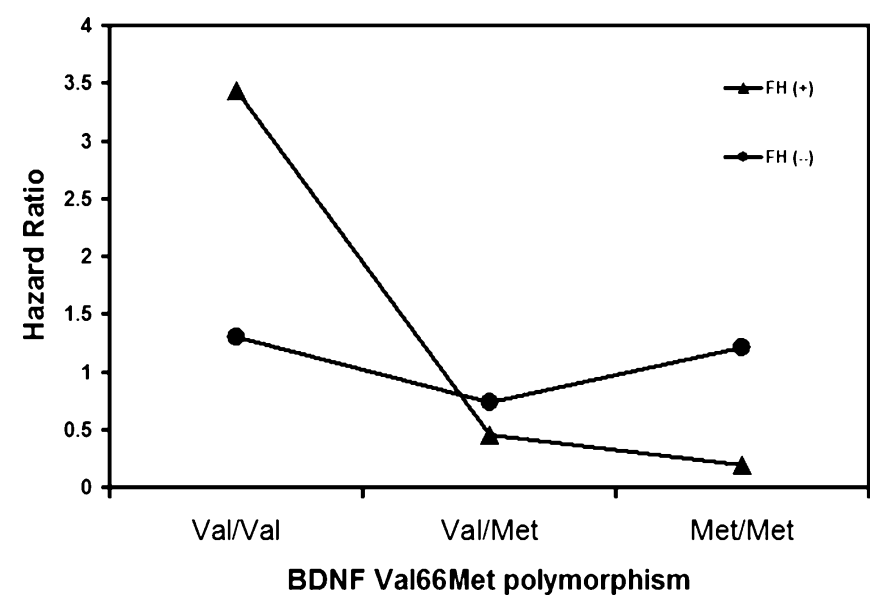

Fig. 2. Interaction between BDNF Val66Met polymorphism and family history of alcohol dependence in relationship to the risk of relapse in alcoholdependent patients $(p=0.026)$.

supplementary analyses now included 154 individuals, 64 of whom were considered as non-relapsed and 90 of whom were now classified as relapsed. In the bivariate analysis, the effect of $B D N F$ Val66 allele on the likelihood of relapse remained significant $\left(\chi^{2}=4.848 ; p=0.028\right)$ as well as the effect on the time to relapse $(F=3.818 ; p=0.025)$. Similarly, in the multivariate models, the effect of $B D N F$ Val66Val genotype on relapse and time to relapse was significant when controlling for other risk factors $(\mathrm{OR}=2.24 ; 95 \% \mathrm{CI}=1.02$ to 4.96; $p=0.046$, and $\mathrm{HR}=2.11 ; 95 \% \mathrm{CI}=1.12$ to 3.97 ; $p=0.021$, respectively).

\section{DISCUSSION}

In this study, the Val66Met BDNF polymorphism predicted relapse and time to relapse among alcohol-dependent patients during the first year following treatment. The shortest times to relapse were found in individuals with the $B D N F$ Val66Val genotype. This genotype was the strongest significant predictor of relapse after controlling for other tested genetic polymorphisms and known risk factors, namely baseline severity of alcohol use, depression, impulsivity, and a history of an impulsive suicide attempt. The relationship was especially pronounced in individuals with a family history of alcohol dependence, suggesting that the BDNF Val66Val genotype interacts with family factors to increase vulnerability to relapse, including either (1) other inherited genetic polymorphisms and/or (2) an influence of family environment. Regardless of whether the mechanism was genetic or environmental, family history moderated the effects of the $B D N F$ polymorphism on risk for relapse. Given the preliminary nature of the literature on genetics and relapse and the number of tests of significance conducted in this study, the results should be considered as hypothesis generating. However, it is important to note, that the relationship between the Val66Met genotype and time to relapse was significant (e.g., $p=0.001)$ even after applying standard corrections for multiple significance tests (correcting for 2 to 3 related phenotypes and 6 polymorphisms).

Although relapse was more frequent in patients with the COMT Val158Met genotype, the COMT polymorphism did not predict relapse in the multivariate models. There were no significant differences in relapse rates or time to relapse across the other tested polymorphisms [HTR1A $\mathrm{C}(-1019) \mathrm{G}$, HTR2A C102T, and TPH2 rs1386483]. The lack of significant association between risk for relapse in alcohol-dependent patients and the $\mathrm{S}$ allele of the 5HTTLPR polymorphism in this study is inconsistent with results previously reported in a sample of 48 individuals by Pinto and colleagues (2008). This may be due to differences in the study sample, different follow up periods, and/or relative lack of power in our sample.

This study suggests that the functioning of BDNF may be particularly important in understanding susceptibility to relapse. BDNF is a neurotrophin involved in the development and survival of neurons, and in modulating the activity of neurotransmitter systems (Lipsky and Marini, 2007; Russo-Neustadt, 2003), particularly 5-HT and DA, which are associated both with suicidality and the development of 
addictions. Some studies have shown that BDNF may play a role in the pathogenesis of depression, anxiety, and suicidal behavior (Duman, 2002; Dwivedi et al., 2003; Hashimoto et al., 2004; Karege et al., 2005; Kim et al., 2007; Levinson, 2006; Nestler et al., 2002; Perroud et al., 2008; Shelton, 2007). More recent reports indicate that BDNF, among other neurotrophic factors, may be directly involved in the pathogenesis and development of alcohol dependence (Davis, 2008; Janak et al., 2006; Joe et al., 2007; Yoon et al., 2006). Uhl and colleagues (2001) identified the $B D N F$ gene locus as linked to vulnerability to nicotine or alcohol use.

Although BDNF has been associated with a number of psychiatric disorders, the differential impact of the $B D N F$ Val66Met polymorphism in psychiatric disorders is less clear. Even though substitution of Val66 by Met in the propeptide of the protein due to a common polymorphism does not affect the sequence of mature BDNF, the Met allele fails to localize the protein to synapses in vitro (Egan et al., 2003), and leads to decreased distribution of BDNF to neuronal dendrites and reduced activity-dependent secretion (Chen et al., 2004, 2006). Individuals with the Met allele had smaller hippocampal volumes (Bueller et al., 2006; Pezawas et al., 2004) and worse performance on hippocampus-dependent memory tasks (Egan et al., 2003). Therefore, the Met allele, responsible for reduced BDNF availability, is considered by many researchers as a risk factor for psychopathology including increased neuroticism, anxiety, depression, and suicide (Enoch et al., 2008; Hashimoto et al., 2004; Hwang et al., 2006; Iga et al., 2007). Indeed, a knock-in mouse model showed decreased hippocampal volume and increased anxiety (Chen et al., 2006).

However, many other studies suggest that the BDNF Val66 is the susceptibility allele, associated with anxiety and mood disorders. Sen and colleagues (2003) showed that the Val66 allele was associated with higher neuroticism scores, and many studies have found a genetic association between the $B D N F$ Val66 allele and susceptibility to major depression (Frodl et al., 2007; Jiang et al., 2005; Pezawas et al., 2008; Schumacher et al., 2005), bipolar disorder (Lohoff et al., 2005; NevesPereira et al., 2002; Sklar et al., 2002), and substance use disorders (Cheng et al., 2005; Graham et al., 2007; Gratacos et al., 2007; Lu et al., 2004). Perroud and colleagues (2008) reported that the $\mathrm{Val} / \mathrm{Val}$ genotype increased the rate of violent suicide attempts among adult victims of childhood sexual abuse. As expected from a complex trait, many studies have not confirmed an association between the BDNF Val66Met and neuroticism, major depression, bipolar disorder, or substance abuse.

Thus far, little research has studied possible links between the $B D N F$ Val66Met polymorphism and alcohol dependence, and most were either negative (Tsai et al., 2005; Zhang et al., 2006) or showed just a trend (Liu et al., 2005). Cheng and colleagues (2005) found that the Val66 allele was associated with dependence on methamphetamine and heroin, and Matsushita and colleagues (2004) found that the 66Met allele predicted a greater severity of alcohol dependence (early onset of the disorder, history of delirium tremens, and violent behavior). In this study, we found an association between the $B D N F$ Val allele and an increased risk for poor treatment outcomesi.e., relapse to any alcohol use and shorter time to relapse. While our result is somewhat at odds with the finding that the $B D N F$ Met allele was associated with greater severity of alcoholism (Matsushita et al., 2004), the latter study did not measure relapse as an outcome variable. The Val allele is essential for "normal" secretion of BDNF and intercellular activity of the neurotrophin. It is, therefore, somewhat surprising that the better functioning genetic variant is associated with relapse to addiction. On the other hand, animal models of craving and relapse found that elevated levels of BDNF in mesolimbic DA areas were associated with an increased likelihood of relapse to cocaine use (Lu et al., 2004). In another study, experimental infusion of BDNF into the nucleus accumbens led to reinstatement of cocaine self-administration in rats (Graham et al., 2007). Therefore, BDNF might be responsible for the persistence of responsiveness to substancerelated cues after withdrawal in alcohol- or drug-dependent individuals. Finally, in individuals treated for alcohol dependence, relapse is a very common outcome. Thus, the association between the more common variant and relapse could primarily reflect the frequency of this genotype.

Results of this study support the hypothesis that the $B D N F$ Val66 allele confers a risk for relapse in alcohol-dependent individuals. Conversely, the Met66 allele may play a protective role against recurrent drinking after treatment for alcohol dependence. Despite lack of direct evidence for this hypothesis, results from other studies (Lohoff et al., 2005; NevesPereira et al., 2002; Perroud et al., 2008; Pezawas et al., 2008; Sen et al., 2003; Sklar et al., 2002) and a neurotrophic theory of depression seem to support the suggestion that the more evolutionarily novel Met allele, while responsible for lower neuronal secretion and decreased activity of BDNF protein may, in fact, have a protective function in the central nervous system. Moreover, by modulating the function of both dopaminergic and serotonergic systems, BDNF may further influence addiction-related neurocircuitry leading to relapse.

There are several limitations to this study. The study sample was relatively small, which limited the power to detect other significant associations and may have biased our results. Patients were recruited from 4 treatment centers in Poland. Compared with countries such as the United States, ethnic variation is limited in Poland, and the results may not readily generalize across other ethnic groups. On the other hand, less diversity in the study sample carries the advantage of analyzing more homogenous phenotypes and genotypes, thereby increasing statistical power relative to the small sample size. Additionally, the study examined relapse after an episode of alcohol treatment; it is not known if results are applicable to alcohol-dependent individuals who never come for treatment. The overall rate of relapse in this study of $48 \%$ is somewhat lower than is typically reported in large observational studies. However, to the best of our knowledge, no comparable studies have been conducted on individuals seeking treatment 
for alcohol dependence in Poland. It is possible that the relatively low rate of relapse in this study is due to the fact that the rate of relapse was much higher in those participants without follow-up data. When individuals lost to follow-up were reclassified as relapsed, the relapse rate increased to $58 \%$. Moreover, supplementary analyses of the relationship between $B D N F$ polymorphism and relapse, which included these individuals with missing follow-up data, remained significant. Nevertheless, the present findings should be considered with caution until they are replicated in larger samples of representative alcohol-dependent populations.

A primary outcome measure, time to relapse to any drinking, was based on a single assessment period of approximately 1 year. Although previous research has demonstrated that timeline follow-back methods can provide accurate data across this time frame (Sobell et al., 1986), the use of multiple assessments of post-treatment drinking might increase the sensitivity and validity of the measure. Recall bias could occur and participants may not accurately remember the exact timing of relapse. However, the general consistency of the findings between the logistic regression (which examined risk of relapse - no vs. yes) and the survival analyses (examining time to relapse) makes it unlikely that incorrect recollection of the exact date of relapse fully accounts for the present findings. Additionally, there is a chance that some of the patients, particularly those in outpatient programs, may have maintained active drinking throughout the study without ever achieving an initial period of abstinence upon starting treatment; thus, the term "relapse" may not accurately capture the pattern of drinking of these patients. However, this possibility is unlikely because of the length and intensity of monitoring in these programs. Self-report was not verified by biochemical measures or independently corroborated. Moreover, it is interesting to note that only 11 individuals lapsed briefly; the majority (48/59) returned to heavy drinking. Although this study lacked sufficient power to distinguish between those with more minor lapses and those with more significant relapses, future research should examine whether specific genotypes could meaningfully differentiate between these groups.

Because this study did not comprehensively assess potential mediators, the exact mechanisms that explain the relationship between BDNF polymorphism and relapse are not known. Knowledge of mechanisms is important for designing targeted treatment interventions. Therefore, future research with multiple assessment points prior to the time of relapse should help to identify potential mediators through which genetics may impact vulnerability to relapse.

To our knowledge, this is the first study to report a significant association between the Val66 allele of $B D N F$ and increased risk for both any and earlier relapse in patients admitted to addiction treatment programs, especially in patients with a family history of alcohol dependence. Our results, which need to be replicated, highlight the importance of identifying genetic factors that may place certain individuals at increased risk for relapse following alcohol treatment.

\section{ACKNOWLEDGMENTS}

This work was supported by the Fogarty International Center/NIDA International Substance Abuse Research Program Grant D43-TW05818, the Fogarty International Center/NIAAA International Collaborative Alcohol \& Injury Research Training Program grant D43-TW007569, NIAAA Grant R21 AA016104, and the Polish Ministry of Science and Higher Education Grant 2P05D 004 29. The views expressed in this report are those of the authors and do not necessarily represent the views of any of the funding agencies. Additionally, none of the funding agencies had any direct involvement in the study design, the collection, analysis and interpretation of data, the writing of the report, or in the decision to submit the paper for publication. We would like to thank all members of the research team in Poland (especially Andrzej Jakubczyk, MD, Anna Wnorowska, MD; Anna Klimkiewicz, MD; Malgorzata Marusa, MS; Aleksandra Konopa, MD; Elzbieta Wozny, PhD; Malgorzata Abramowska, MSc) as well as the medical staff and patients at "Kolska," "Pruszkow," "Petra," and "Solec" Addiction Treatment Centers in Warsaw for their support of this research.

\section{CONFLICT OF INTEREST}

All authors declare that they have no conflicts of interest.

\section{REFERENCES}

Allen TJ, Moeller FG, Rhoades HM, Cherek DR (1998) Impulsivity and history of drug dependence. Drug Alcohol Depend 50:137-145.

APA (American Psychiatric Association) (2000) Diagnostic and Statistical Manual of Mental Disorders, 4th ed, Text Revision. American Psychiatric Association, Washington, DC.

Barratt ES (1959) Anxiety and impulsiveness related to psychomotor efficiency. Percept Motor Skills 9:191-198.

Bauer LO (2001) Predicting relapse to alcohol and drug abuse via quantitative electroencephalography. Neuropsychopharmacology 25:332-340.

Bauer LO, Covault J, Harel O, Das S, Gelernter J, Anton R, Kranzler HR (2007) Variation in GABRA2 predicts drinking behavior in project MATCH subjects. Alcohol Clin Exp Res 31:1780-1787.

Beck AT, Steer RA, Brown G (1996) Manual of the Beck Depression Inventory II. Psychological Corporation, San Antonio, TX.

Bottlender M, Soyka M (2005) Outpatient alcoholism treatment: predictors of outcome after 3 years. Drug Alcohol Depend 80:83-89.

Brower KJ, Aldrich MS, Hall JM (1998) Polysomnographic and subjective sleep predictors of alcoholic relapse. Alcohol Clin Exp Res 22:1864-1871.

Bueller JA, Aftab M, Sen S, Gomez-Hassan D, Burmeister M, Zubieta JK (2006) BDNF Val66Met allele is associated with reduced hippocampal volume in healthy subjects. Biol Psychiatry 59:812-815.

Chen ZY, Jing D, Bath KG, Ieraci A, Khan T, Siao CJ, Herrera DG, Toth M, Yang C, McEwen BS, Hempstead BL, Lee FS (2006) Genetic variant BDNF (Val66Met) polymorphism alters anxiety-related behavior. Science 314:140-143.

Chen ZY, Patel PD, Sant G, Meng CX, Teng KK, Hempstead BL, Lee FS (2004) Variant brain-derived neurotrophic factor (BDNF) (Met66) alters the intracellular trafficking and activity-dependent secretion of wild-type BDNF in neurosecretory cells and cortical neurons. J Neurosci 24:4401-4411.

Cheng CY, Hong CJ, Yu YW, Chen TJ, Wu HC, Tsai SJ (2005) Brain-derived neurotrophic factor (Val66Met) genetic polymorphism is associated with substance abuse in males. Brain Res Mol Brain Res 140:86-90. 
Covault J, Gelernter J, Hesselbrock V, Nellissery M, Kranzler HR (2004) Allelic and haplotypic association of GABRA2 with alcohol dependence. Am J Med Genet 129B:104-109.

Davis MI (2008) Ethanol-BDNF interactions: still more questions than answers. Pharmacol Ther 118:36-57.

Derogatis LR, Melisaratos N (1983) The Brief Symptom Inventory: an introductory report. Psychol Med 13:595-605.

Duman RS (2002) Synaptic plasticity and mood disorders. Mol Psychiatry 7(Suppl. 1):S29-S34.

Dwivedi Y, Rizavi HS, Conley RR, Roberts RC, Tamminga CA, Pandey GN (2003) Altered gene expression of brain-derived neurotrophic factor and receptor tyrosine kinase B in postmortem brain of suicide subjects. Arch Gen Psychiatry 60:804-815.

Edenberg HJ (2007) The genetics of alcohol metabolism: role of alcohol dehydrogenase and aldehyde dehydrogenase variants. Alcohol Res Health 30:513.

Edenberg HJ, Foroud T (2006) The genetics of alcoholism: identifying specific genes through family studies. Addict Biol 11:386-396.

Edenberg HJ, Kranzler HR (2005) The contribution of genetics to addiction therapy approaches. Pharmacol Ther 108:86-93.

Egan MF, Kojima M, Callicott JH, Goldberg TE, Kolachana BS, Bertolino A, Zaitsev E, Gold B, Goldman D, Dean M, Lu B, Weinberger DR (2003) The BDNF val66met polymorphism affects activity-dependent secretion of BDNF and human memory and hippocampal function. Cell 112:257-269.

Enoch MA, White KV, Waheed J, Goldman D (2008) Neurophysiological and genetic distinctions between pure and comorbid anxiety disorders Depress Anxiety 25:383-392.

Finckh U, Rommelspacher H, Kuhn S, Dufeu P, Otto G, Heinz A, Dettling M, Giraldo-Velasquez M, Pelz J, Graf KJ, Harms H, Sander T, Schmidt LG, Rolfs A (1997) Influence of the dopamine D2 receptor (DRD2) genotype on neuroadaptive effects of alcohol and the clinical outcome of alcoholism. Pharmacogenetics 7:271-281.

Frodl T, Schule C, Schmitt G, Born C, Baghai T, Zill P, Bottlender R, Rupprecht R, Bondy B, Reiser M, Moller HJ, Meisenzahl EM (2007) Association of the brain-derived neurotrophic factor Val66Met polymorphism with reduced hippocampal volumes in major depression. Arch Gen Psychiatry 64:410-416.

Gann H, Feige B, Hohagen F, van Calker D, Geiss D, Dieter R (2001) Sleep and the cholinergic rapid eye movement sleep induction test in patients with primary alcohol dependence. Biol Psychiatry 50:383-390.

Gelernter J, Kranzler H, Coccaro EF, Siever LJ, New AS (1998) Serotonin transporter protein gene polymorphism and personality measures in African American and European American subjects. Am J Psychiatry 155:13321338.

George DT, Rawlings R, Eckardt MJ, Phillips MJ, Shoaf SE, Linnoila M (1999) Buspirone treatment of alcoholism: age of onset, and cerebrospinal fluid 5-hydroxyindolacetic acid and homovanillic acid concentrations, but not medication treatment, predict return to drinking. Alcohol Clin Exp Res 23:272-278.

Glenn SW, Sinha R, Parsons OA (1993) Electrophysiological indices predict resumption of drinking in sober alcoholics. Alcohol 10:89-95.

Gorwood P, Batel P, Ades J, Hamon M, Boni C (2000) Serotonin transporter gene polymorphisms, alcoholism, and suicidal behavior. Biol Psychiatry 48:259-264

Graham DL, Edwards S, Bachtell RK, DiLeone RJ, Rios M, Self DW (2007) Dynamic BDNF activity in nucleus accumbens with cocaine use increases self-administration and relapse. Nat Neurosci 10:1029-1037.

Gratacos M, Gonzalez JR, Mercader JM, de Cid R, Urretavizcaya M, Estivill X (2007) Brain-derived neurotrophic factor Val66Met and psychiatric disorders: meta-analysis of case-control studies confirm association to substance-related disorders, eating disorders, and schizophrenia. Biol Psychiatry 61:911-922.

Gscheidel N, Sander T, Wendel B, Heere P, Schmidt LG, Rommelspacher H, Hoehe MR, Samochowiec J (2000) Five exon 1 variants of mu opioid receptor and vulnerability to alcohol dependence. Pol J Pharmacol 52: $27-31$.
Guardia J, Catafau AM, Batlle F, Martin JC, Segura L, Gonzalvo B, Prat G, Carrio I, Casas M (2000) Striatal dopaminergic D(2) receptor density measured by [(123)I]iodobenzamide SPECT in the prediction of treatment outcome of alcohol-dependent patients. Am J Psychiatry 157:127-129.

GUS (Gówny Urząd Statystyczny) (2006) Annual Statistic Data. GUS, Warsaw.

Hashimoto K, Shimizu E, Iyo M (2004) Critical role of brain-derived neurotrophic factor in mood disorders. Brain Res Brain Res Rev 45:104-114.

Heinz A, Sander T, Harms H, Finckh U, Kuhn S, Dufeu P, Dettling M, Graf K, Rolfs A, Rommelspacher H, Schmidt LG (1996) Lack of allelic association of dopamine D1 and D2 (TaqIA) receptor gene polymorphisms with reduced dopaminergic sensitivity to alcoholism. Alcohol Clin Exp Res 20:1109-1113.

Hwang JP, Tsai SJ, Hong CJ, Yang CH, Lirng JF, Yang YM (2006) The Val66Met polymorphism of the brain-derived neurotrophic-factor gene is associated with geriatric depression. Neurobiol Aging 27:1834-1837.

Iga J, Ueno S, Yamauchi K, Numata S, Tayoshi-Shibuya S, Kinouchi S, Nakataki M, Song H, Hokoishi K, Tanabe H, Sano A, Ohmori T (2007) The Val66Met polymorphism of the brain-derived neurotrophic factor gene is associated with psychotic feature and suicidal behavior in Japanese major depressive patients. Am J Med Genet B Neuropsychiatr Genet 144B:10031006.

Janak PH, Wolf FW, Heberlein U, Pandey SC, Logrip ML, Ron D (2006) BIG news in alcohol addiction: new findings on growth factor pathways BDNF, insulin, and GDNF. Alcohol Clin Exp Res 30:214-221.

Jiang X, Xu K, Hoberman J, Tian F, Marko AJ, Waheed JF, Harris CR, Marini AM, Enoch MA, Lipsky RH (2005) BDNF variation and mood disorders: a novel functional promoter polymorphism and Val66Met are associated with anxiety but have opposing effects. Neuropsychopharmacology 30:1353-1361

Joe KH, Kim YK, Kim TS, Roh SW, Choi SW, Kim YB, Lee HJ, Kim DJ (2007) Decreased plasma brain-derived neurotrophic factor levels in patients with alcohol dependence. Alcohol Clin Exp Res 31:1833-1838.

Karege F, Vaudan G, Schwald M, Perroud N, La Harpe R (2005) Neurotrophin levels in postmortem brains of suicide victims and the effects of antemortem diagnosis and psychotropic drugs. Brain Res Mol Brain Res 136:29-37.

Kia-Keating BM, Glatt SJ, Tsuang MT (2007) Meta-analyses suggest association between COMT, but not HTR1B, alleles, and suicidal behavior. Am J Med Genet B Neuropsychiatr Genet 144B:1048-1053.

Kim YK, Lee HP, Won SD, Park EY, Lee HY, Lee BH, Lee SW, Yoon D, Han C, Kim DJ, Choi SH (2007) Low plasma BDNF is associated with suicidal behavior in major depression. Prog Neuropsychopharmacol Biol Psychiatry $31: 78-85$.

Lemonde S, Turecki G, Bakish D, Du L, Hrdina PD, Bown CD, Sequeira A, Kushwaha N, Morris SJ, Basak A, Ou XM, Albert PR (2003) Impaired repression at a 5-hydroxytryptamine $1 \mathrm{~A}$ receptor gene polymorphism associated with major depression and suicide. J Neurosci 23:8788-8799.

Levinson DF (2006) The genetics of depression: a review. Biol Psychiatry 60:84-92.

Li D, He L (2007) Meta-analysis supports association between serotonin transporter (5-HTT) and suicidal behavior. Mol Psychiatry 12:47-54.

Lipsky RH, Marini AM (2007) Brain-derived neurotrophic factor in neuronal survival and behavior-related plasticity. Ann NY Acad Sci 1122:130-143.

Liu QR, Walther D, Drgon T, Polesskaya O, Lesnick TG, Strain KJ, de Andrade M, Bower JH, Maraganore DM, Uhl GR (2005) Human brain derived neurotrophic factor (BDNF) genes, splicing patterns, and assessments of associations with substance abuse and Parkinson's disease. Am J Med Genet B Neuropsychiatr Genet 134B:93-103.

Lohoff FW, Sander T, Ferraro TN, Dahl JP, Gallinat J, Berrettini WH (2005) Confirmation of association between the Val66Met polymorphism in the brain-derived neurotrophic factor (BDNF) gene and bipolar I disorder. Am J Med Genet B Neuropsychiatr Genet 139B:51-53.

Lu L, Grimm JW, Hope BT, Shaham Y (2004) Incubation of cocaine craving after withdrawal: a review of preclinical data. Neuropharmacology 47(Suppl. 1):214-226. 
Mann K, Schafer DR, Langle G, Ackermann K, Croissant B (2005) The longterm course of alcoholism, 5, 10 and 16 years after treatment. Addiction 100:797-805.

Marchesi C, Chiodera P, Ampollini P, Volpi R, Coiro V (1997) Betaendorphin, adrenocorticotropic hormone and cortisol secretion in abstinent alcoholics. Psychiatry Res 72:187-194.

Matsushita S, Kimura M, Miyakawa T, Yoshino A, Murayama M, Masaki T, Higuchi S (2004) Association study of brain-derived neurotrophic factor gene polymorphism and alcoholism. Alcohol Clin Exp Res 28:1609-1612.

Nestler EJ, Barrot M, DiLeone RJ, Eisch AJ, Gold SJ, Monteggia LM (2002) Neurobiology of depression. Neuron 34:13-25.

Neves-Pereira M, Mundo E, Muglia P, King N, Macciardi F, Kennedy JL (2002) The brain-derived neurotrophic factor gene confers susceptibility to bipolar disorder: evidence from a family-based association study. Am J Hum Genet 71:651-655.

Perroud N, Courtet P, Vincze I, Jaussent I, Jollant F, Bellivier F, Leboyer M, Baud P, Buresi C, Malafosse A (2008) Interaction between BDNF Val66Met and childhood trauma on adult's violent suicide attempt. Genes Brain Behav 7:314-322.

Pezawas L, Meyer-Lindenberg A, Goldman AL, Verchinski BA, Chen G, Kolachana BS, Egan MF, Mattay VS, Hariri AR, Weinberger DR (2008) Evidence of biologic epistasis between BDNF and SLC6A4 and implications for depression. Mol Psychiatry 13:654.

Pezawas L, Verchinski BA, Mattay VS, Callicott JH, Kolachana BS, Straub RE, Egan MF, Meyer-Lindenberg A, Weinberger DR (2004) The brainderived neurotrophic factor val66met polymorphism and variation in human cortical morphology. J Neurosci 24:10099-10102.

Pinto E, Reggers J, Gorwood P, Boni C, Scantamburlo G, Pitchot W, Ansseau M (2008) The short allele of the serotonin transporter promoter polymorphism influences relapse in alcohol dependence. Alcohol Alcohol 43:398-400.

Polich JM, Armor DJ, Braiker HB (1980) Patterns of alcoholism over four years. J Stud Alcohol 41:397-416.

Preuss UW, Koller G, Bondy B, Bahlmann M, Soyka M (2001) Impulsive traits and 5-HT2A receptor promoter polymorphism in alcohol dependents: possible association but no influence of personality disorders. Neuropsychobiology 43:186-191.

Project MATCH (1997) Matching alcoholism treatments to client heterogeneity: Project MATCH posttreatment drinking outcomes. J Stud Alcohol 58:7-29.

Russo-Neustadt A (2003) Brain-derived neurotrophic factor, behavior, and new directions for the treatment of mental disorders. Semin Clin Neuropsychiatry 8:109-118.

Schmidt LG, Dettling M, Graef KJ, Heinz A, Kuhn S, Podschus J, Rommelspacher H (1996) Reduced dopaminergic function in alcoholics is related to severe dependence. Biol Psychiatry 39:193-198.

Schumacher J, Jamra RA, Becker T, Ohlraun S, Klopp N, Binder EB, Schulze TG, Deschner M, Schmal C, Hofels S, Zobel A, Illig T, Propping P, Holsboer F, Rietschel M, Nothen MM, Cichon S (2005) Evidence for a relationship between genetic variants at the brain-derived neurotrophic factor (BDNF) locus and major depression. Biol Psychiatry 58:307-314.

Sen S, Nesse RM, Stoltenberg SF, Li S, Gleiberman L, Chakravarti A, Weder $\mathrm{AB}$, Burmeister M (2003) A BDNF coding variant is associated with the NEO personality inventory domain neuroticism, a risk factor for depression. Neuropsychopharmacology 28:397-401.

Sen S, Villafuerte S, Nesse R, Stoltenberg SF, Hopcian J, Gleiberman L, Weder A, Burmeister M (2004) Serotonin transporter and GABAA alpha 6 receptor variants are associated with neuroticism. Biol Psychiatry $55: 244-249$.

Serretti A, Mandelli L, Giegling I, Schneider B, Hartmann AM, Schnabel A, Maurer K, Moller HJ, Rujescu D (2007) HTR2C and HTR1A gene variants in German and Italian suicide attempters and completers. Am J Med Genet B Neuropsychiatr Genet 144B:291-299.
Sheehan DV, Lecrubier Y, Sheehan KH, Amorim P, Janavs J, Weiller E, Hergueta T, Baker R, Dunbar GC (1998) The Mini-International Neuropsychiatric Interview (M.I.N.I.): the development and validation of a structured diagnostic psychiatric interview for DSM-IV and ICD-10. J Clin Psychiatry 59(Suppl. 20):22-33.

Shelton RC (2007) The molecular neurobiology of depression. Psychiatr Clin North Am 30:1-11.

Sklar P, Gabriel SB, McInnis MG, Bennett P, Lim YM, Tsan G, Schaffner S, Kirov G, Jones I, Owen M, Craddock N, DePaulo JR, Lander ES (2002) Family-based association study of 76 candidate genes in bipolar disorder: $\mathrm{BDNF}$ is a potential risk locus. Brain-derived neutrophic factor. Mol Psychiatry 7:579-593.

Smith GE, Ross RL, Rost KM (1996) Psychiatric outcomes module: Substance Abuse Outcomes Module (SAOM), in Outcome Assessment in Clinical Practice (Sederer LI, Dickey B eds), pp 85-88. Williams and Wilkins, Baltimore, MD.

Sobell LC, Maisto SA, Sobell MB, Cooper AM (1979) Reliability of alcohol abusers' self-reports of drinking behavior. Behav Res Ther 17:157-160.

Sobell MB, Sobell LC, Klajner F, Pavan D, Basian E (1986) The reliability of a timeline method for assessing normal drinker college students' recent drinking history: utility for alcohol research. Addict Behav 11:149-161.

Sobell LC, Sobell MB, Leo GI, Cancilla A (1988) Reliability of a timeline method: assessing normal drinkers' reports of recent drinking and a comparative evaluation across several populations. Br J Addict 83:393-402.

Stoltenberg SF, Glass JM, Chermack ST, Flynn HA, Li S, Weston ME, Burmeister M (2006) Possible association between response inhibition and a variant in the brain-expressed tryptophan hydroxylase-2 gene. Psychiatr Genet 16:35-38.

Tsai SJ, Liao DL, Yu YW, Chen TJ, Wu HC, Lin CH, Cheng CY, Hong CJ (2005) A study of the association of (Val66Met) polymorphism in the brainderived neurotrophic factor gene with alcohol dependence and extreme violence in Chinese males. Neurosci Lett 381:340-343.

Uhl GR, Liu QR, Walther D, Hess J, Naiman D (2001) Polysubstance abusevulnerability genes: genome scans for association, using 1,004 subjects and 1,494 single-nucleotide polymorphisms. Am J Hum Genet 69:1290-1300.

Vaquero-Lorenzo C, Baca-Garcia E, Diaz-Hernandez M, Perez-Rodriguez MM, Fernandez-Navarro P, Giner L, Carballo JJ, Saiz-Ruiz J, FernandezPiqueras J, Baldomero EB, de Leon J, Oquendo MA (2007) Association study of two polymorphisms of the serotonin-2A receptor gene and suicide attempts. Am J Med Genet B Neuropsychiatr Genet 147B:645-649.

Wang T, Franke P, Neidt H, Cichon S, Knapp M, Lichtermann D, Maier W, Propping P, Nothen MM (2001) Association study of the low-activity allele of catechol-O-methyltransferase and alcoholism using a family-based approach. Mol Psychiatry 6:109-111.

Wiesbeck GA, Weijers HG, Wodarz N, Herrmann MJ, Johann M, Keller HK, Michel TM, Boning J (2003) Dopamine D2 (DAD2) and dopamine D3 (DAD3) receptor gene polymorphisms and treatment outcome in alcohol dependence. J Neural Transm 110:813-820.

Wojnar M, Ilgen MA, Jakubczyk A, Wnorowska A, Klimkiewicz A, Brower KJ (2008) Impulsive suicide attempts predict post-treatment relapse in alcohol-dependent patients. Drug Alcohol Depend 97:268-275.

Yoon SJ, Roh S, Lee H, Lee JY, Lee BH, Kim YK, Kim DJ (2006) Possible role of nerve growth factor in the pathogenesis of alcohol dependence. Alcohol Clin Exp Res 30:1060-1065.

Zhang X, Beaulieu JM, Gainetdinov RR, Caron MG (2006) Functional polymorphisms of the brain serotonin synthesizing enzyme tryptophan hydroxylase-2. Cell Mol Life Sci 63:6-11.

Zhou Z, Roy A, Lipsky R, Kuchipudi K, Zhu G, Taubman J, Enoch MA, Virkkunen M, Goldman D (2005) Haplotype-based linkage of tryptophan hydroxylase 2 to suicide attempt, major depression, and cerebrospinal fluid 5-hydroxyindoleacetic acid in 4 populations. Arch Gen Psychiatry 62:1109-1118. 